\title{
LA CABEZONA, TAMBO DE LA MEMORIA: EL PATRIMONIO COMO MEMORIA SOCIAL: REPRESENTACIÓN DEL PASADO E IDENTIDAD CULTURAL EN LA CIUDAD HISTÓRICA HABITADA DE AREQUIPA
}

\author{
M. LOAYZA VELA Y C. SUBiA NARVÁEZ \\ ASOCIACIÓN CULTURAL APOYOMUTUO, LIMA, PERÚ, 2018.
}

RESEÑA DE SALY PALPÁN LÓPEZ

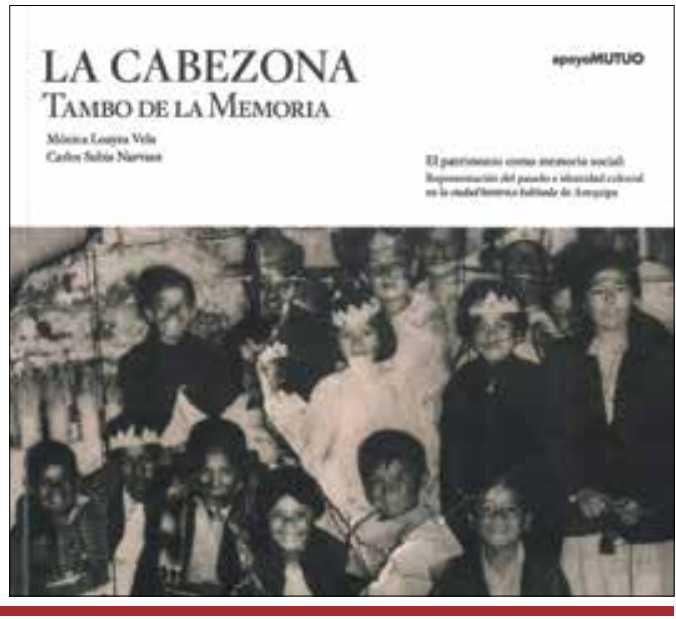

El tambo La Cabezona, ubicado en el Centro Histórico de Arequipa, ha sido lugar de un proyecto que busca recuperar el concepto de ciudad histórica habitable, a través del esfuerzo conjunto de intervenciones de colectivos culturales, ciudadanos independientes e instituciones. La experiencia de este proyecto ha sido plasmada en La Cabezona, Tambo de la Memoria, libro ganador de la Convocatoria 2017 de Sistematización de Experiencias y Publicaciones de Puntos de Cultura del Ministerio de Cultura del Perú.

La ideal esencial de este proyecto es la convicción de que es necesaria una mirada holística e interdisciplinaria de la conservación del patrimonio, la cual no prioriza la valoración del objeto desde su materialidad, sino que reivindica a los sujetos patrimoniales y la memoria colectiva como agentes activos en su preservación. Diversos actores sociales colaboran para este propósito: Puntos de Cultura Apoyo Mutuo, la ONG Mandala, el Laboratorio de Investigación Urbana La Nube y, como protagonistas principales, los habitantes del tambo, cuyas relaciones cotidianas en el pasado, presente y futuro del patrimonio son el medio para reformular la apropiación social y simbólica que finalmente busca construir ciudadanía e identidad.

Estas relaciones patrimoniales son presentadas al lector a través de testimonios que desde diferentes voces estructuran el libro en tres partes: "Ios otros", "nosotros" y "ustedes". Esta narrativa se centra en concebir al patrimonio desde la mirada de los otros, quienes fueron al encuentro y exploración del tambo; desde un nosotros compuesto por quienes habitan y conviven con el patrimonio; $y$, finalmente, desde un "ustedes" que transmite a los lectores las reflexiones y conclusiones finales de la experiencia. Esto evidencia una perspectiva alternativa frente al complejo problema de la conservación patrimonial en los centros históricos peruanos: la posibilidad de reconocer a la memoria colectiva y los valores intangibles asociados al patrimonio como catalizadores de actividades en entornos urbanos históricos, sectores de ciudad, poblados históricos o centros históricos, los cuales se alimentan principalmente de ese nosotros compuesto por las comunidades que conviven y habitan el patrimonio, los herederos y beneficiarios finales que los revaloran como espacios de encuentro ciudadano.

El valor otorgado al testimonio como base para comunicar y conectar con el lector es resaltante. Se utilizan diferentes herramientas digitales y físicas para recoger los testimonios, como archivos fotográficos, y relatos orales centrados en transmitir sentimientos, esperanzas y recuerdos de los vecinos y amigos del tambo, de todas las generaciones que se han albergado en sus espacios, de las orgullosas iniciativas deportivas que nacieron ahí bajo el título "Sport Chili: Entre el río, la vida cotidiana y el juego". El archivo de relatos orales enlaza el libro con una plataforma virtual que reúne la memoria local, la cual es accesible mediante los códigos QR insertos en la publicación. La recopilación de testimonios, así como la revaloración de la memoria colectiva, ha derivado en la creación de una memoteca que reivindica la valoración patrimonial a partir de aspectos cualitativos, sentimentales y afectivos. De esta manera, el proyecto busca la apropiación simbólica y el reconocimiento de "los otros, nosotros y ustedes" como ciudadanos; $y$, por lo tanto, expresa el derecho y deber de ser parte de la construcción del patrimonio, para así garantizar su continuidad y transcendencia.

En la última parte, se reconoce a los tambos arequipeños como espacios de lucha y resistencia frente a fenómenos urbanos como la gentrificación, la privatización de espacios públicos y la mercantilización de las ciudades históricas. La convivencia vecinal que se mantiene en el tambo La Cabezona y la valoración de las costumbres hacen frente a una lógica que prioriza la función comercial de los centros históricos, y ocasiona la pérdida de funciones que los convierten en espacios de encuentro cívico y democrático: centros históricos donde las políticas de fomento al turismo pueden terminar convirtiendo a los tambos en casas-museo.

Este breve libro - Ileno de nuevas perspectivas y estrategias para la conservación del patrimonio-contiene testimonios $y$, al mismo tiempo, es testimonio de que la sinergia de diferentes actores urbanos en la construcción de un patrimonio de uso social es posible si apostamos por los valores y sentimientos que posee la memoria colectiva, y nos reconocemos a nosotros mismos como protagonistas que crean, transforman y resignifican dicha memoria.

Como colofón, son destacables las palabras de los autores Mónica Loayza y Carlos Subia, quienes señalan que "lo importante aquí, no son los atributos del contenedor, sino las cualidades del entorno compartido donde los otros, nosotros y ustedes entremos en disonancia y contradicción, pero con la idea clara que detrás de cada proyecto se esconden evidentes compromisos humanos y verdaderas ocasiones de hacer ciudad" (p. 5). 